\title{
Effect of transverse distribution profile of thulium on the performance of thulium-doped fibre amplifiers
}

\author{
${ }^{1}$ Emami S.D., ${ }^{2}$ Abdul-Rashid H.A., ${ }^{3}$ Ahmad H., ${ }^{2}$ Ahmadi A. \\ and ${ }^{1}$ Harun S.W. \\ ${ }^{1}$ Department of Electrical Engineering, Faculty of Engineering, University of \\ Malaya, 50603 Kuala Lumpur, Malaysia \\ ${ }^{2}$ Faculty of Engineering, Multimedia University, 63100 Cyberjaya, Malaysia \\ ${ }^{3}$ Photonics Research Center, Department of Physics, University of Malaya, \\ 50603 Kuala Lumpur, Malaysia, e-mail: swharun@um.edu.my
}

Received: 11.11 .2011

\begin{abstract}
We study numerical models for different transverse thulium distribution profiles (TTDPs) characterising the fibres used in thulium-doped fibre amplifiers (TDFAs). Our models consider the overlap factor and the absorption/emission dynamics. Basing on the radial TTDP function of the form $n_{T}(r)=n_{T, \max } \exp \left[-(|r-\delta| / \theta)^{\beta}\right]$, we show that the TDFA gain increases with increasing $\beta$ parameter and decreases as the $\theta$ parameter increases from 1 up to $3 \mu \mathrm{m}$, due to the overlap factor which affects the absorption and emission dynamics of the TDFA. The overlap factor increases with increasing $\beta$ and decreases with increasing $\theta$ value. Finally, the noise figure increases as $\theta$ does so, due to suppression of the amplified spontaneous emission.
\end{abstract}

Keywords: thulium-doped fibres, thulium distribution profile

PACS: 42.81.-I, 42.55.Wd, 42.79.-e

UDC: 535.681 .7 .068

\section{Introduction}

Due to tremendous increase in communication traffics in recent years, a lot of efforts have been directed to the development of efficient broadband fibre amplifiers that can fully exploit low-loss band of silica fibres ranging from $1460 \mathrm{~nm}$ to $1630 \mathrm{~nm}$ [1]. Thulium-doped fibre amplifiers (TDFAs) based on fluoride are a promising candidate for the S-band amplification because their amplification bandwidth is centred at $1470 \mathrm{~nm}$ [2]. This has also spurred many theoretical studies on the topic, which should optimise such major parameters of the rare-earth doped fibre amplifiers as the fibre length and the pump power [3]. In the previous works, optimization of the erbium dopant distribution profile in the core of the doped fibre has been demonstrated to increase the gain and improve the noise figure of the amplifiers $[4,5]$. In the numerical modelling of TDFAs, earlier approaches have assumed that the thulium transverse distribution profile (TTDP) is steplike. There is still a lack of numerical studies on the TDFAs that employ the fibres with different TTDPs which can easily be fabricated [6]. In this work, we investigate numerically the TDFA performance for the case of relatively general TTDPs.

\section{Modelling of thulium-doped fibre amplifier}

Fig. 1 shows quantum transitions for the thulium ions doping a fluoride glass under the condition of pumping at $1050 \mathrm{~nm}$ [7]. There is a number of principal emission lines, in particular the $800 \mathrm{~nm}$ emission resulting from the ${ }^{3} \mathrm{H}_{4}$ to ${ }^{3} \mathrm{H}_{6}$ transition [8] and the 1800-nm emission from the ${ }^{3} \mathrm{~F}_{4}$ to ${ }^{3} \mathrm{H}_{6}$ 
transition [9]. Moreover, there are also photons emitted in the region of $1460 \mathrm{~nm}$ due to the ${ }^{3} \mathrm{H}_{4}$ to ${ }^{3} \mathrm{~F}_{4}$ transition, which is used for the S-band amplification [7]. The amplification is possible via the up-conversion pumping technique so that a population inversion between the ${ }^{3} \mathrm{H}_{4}$ and ${ }^{3} \mathrm{~F}_{4}$ levels can be achieved [10]. The 1050-nm pump excites trivalent thulium ions which populate the ground state and then these excitations decay non-radiatively through ${ }^{3} \mathrm{H}_{6}$ to ${ }^{3} \mathrm{H}_{5}$ levels to the ${ }^{3} \mathrm{~F}_{4}$ level [7]. The ions at this level then absorb another photon from the 1050 -nm pump to be elevated and populate the ${ }^{3} \mathrm{~F}_{2}$ level before relaxing to the ${ }^{3} \mathrm{H}_{4}$ level. Then, these ions absorb the third $1050-\mathrm{nm}$ pump photon to be excited to the ${ }^{1} \mathrm{G}_{4}$ level. The ground-state absorption and the excited-state absorptions in this system are provided by the $1050 \mathrm{~nm}$-pump alone.

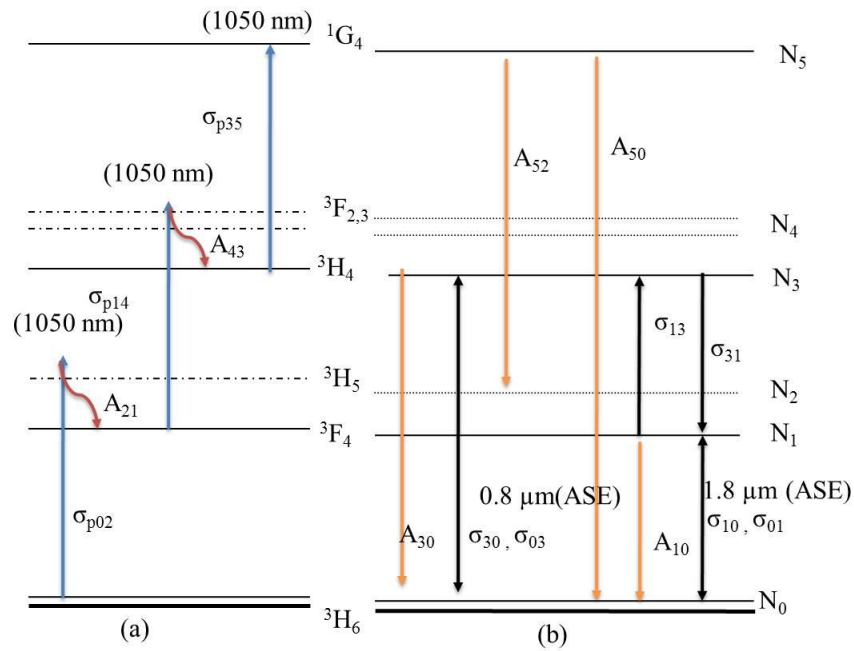

Fig. 1. Illustration of absorption and emission quantum transitions of thulium ions.

We investigate the performance of the TDFA using a basic architecture with the forward 1050-nm pumping. A wavelength division multiplexing coupler is used to combine the pumping source and the input signal, whereas two optical isolators are deployed at both ends of the amplifier to ensure the unidirectional operation. The wave equations for the light propagation along the thulium-doped fibre (TDF) may be written as follows [10]:

$$
\begin{aligned}
& \frac{d P_{A S E}^{ \pm}}{d z}= \pm \Gamma\left(\lambda_{A S E}\right)\left(\sigma_{s e} N_{3}-\sigma_{s a} N_{1}+\sigma_{02} N_{0}\right) \times P_{A S E}^{ \pm} \pm \Gamma\left(\lambda_{A S E}\right) 2 h v \Delta v \sigma_{s e} N_{3} \mp \propto P_{A S E}^{ \pm}, \\
& \frac{d P_{A S E}^{8 \pm}}{d z}= \pm \Gamma\left(\lambda_{8}\right)\left(\sigma_{30} N_{3}-\sigma_{03} N_{0}\right) \times P_{A S E}^{8 \pm} \pm \Gamma\left(\lambda_{8}\right) 2 h v \Delta v \sigma_{30} N_{3} \mp \propto P_{A S E}^{8 \pm}, \\
& \frac{d P_{A S E}^{18 \pm}}{d z}= \pm \Gamma\left(\lambda_{18}\right)\left(\sigma_{s e} N_{3}-\sigma_{03} N_{1}\right) \times P_{A S E}^{8 \pm} \pm \Gamma\left(\lambda_{8}\right) 2 h v \Delta v \sigma_{30} N_{3} \mp \propto P_{A S E}^{8 \pm}, \\
& \frac{d P_{P 1}^{+}}{d z}=-\Gamma\left(\lambda_{P 1}\right)\left(\sigma_{02} N_{0}+\sigma_{14} N_{1}\right) \times P_{P 1}^{+}-\propto P_{P 1}^{-}, \\
& \frac{d P_{S}^{ \pm}}{d z}=\Gamma\left(\lambda_{S}\right)\left(\sigma_{s e} N_{3}-\sigma_{s a} N_{1}+\sigma_{02} N_{0}\right) \times P_{S}^{ \pm} \mp \propto P_{S}^{ \pm} .
\end{aligned}
$$

where the variables $N_{0}, N_{1}, N_{2}$ and $N_{3}$ are used to represent the ion populations for the ${ }^{3} \mathrm{H}_{6},{ }^{3} \mathrm{~F}_{4},{ }^{3} \mathrm{H}_{5}$ and ${ }^{3} \mathrm{H}_{4}$ levels, respectively. The parameters $\sigma_{02}, \sigma_{14}$ and $\sigma_{35}$ are the absorption cross sections of the 1050-nm forward pumping respectively for the ${ }^{3} \mathrm{H}_{6}$ to ${ }^{3} \mathrm{H}_{5},{ }^{3} \mathrm{~F}_{4}$ to ${ }^{3} \mathrm{~F}_{2}$ and ${ }^{3} \mathrm{H}_{4}$ to ${ }^{1} \mathrm{G}_{4}$ transitions, Ukr. J. Phys. Opt. 2012, V13, №2 
$\sigma_{03}$ and $\sigma_{30}, \sigma_{01}$ and $\sigma_{10}$ represent the stimulated absorption and stimulated emission cross sections for the amplified spontaneous emissions (ASEs) respectively at the wavelength of $800 \mathrm{~nm}$ and $1800 \mathrm{~nm}$, while $\sigma_{s a}$ and $\sigma_{s e}$ denote the stimulated absorption and stimulated emission cross sections of the signal from the ${ }^{3} \mathrm{H}_{4}-{ }^{3} \mathrm{~F}_{4}$ transition. Finally, $P_{P 1}^{+}$is the spectral power radiation of the 1050-nm pump, $P_{S}$ the signal power, $P_{A S E}^{8}$ and $P_{A S E}^{18}$ the amplified 800-nm and 1800-nm ASEs in the forward ( + ) and backward (-) directions along the fibre, $A_{\text {eff }}$ the effective area of the TDF, $h$ the Planck constant, and $v$ and $\Delta v$ respectively the light frequency and the bandwidth.

The stimulated absorption and emission from the thulium ions happen when the optical mode overlaps with the distribution of the thulium ions. The overlap factor $\Gamma(\lambda)$ may be represented as [11]

$$
\Gamma(\lambda)=\frac{2 \pi}{N_{T}} \int_{0}^{\infty} \Psi(r, v) \times n_{T}(r) \times r d r
$$

where $\Psi(r, v)$ is the $L P_{01}$-mode envelope, which is almost Gaussian-like. It can be defined as [12]

$$
\Psi(r, v)=\left\{\begin{array}{ll}
j_{0}^{2}\left(u_{k} r / a\right) & r \leq a \\
\frac{j_{0}^{2}\left(u_{k}\right)}{K_{0}^{2}\left(w_{k}\right)} K_{0}^{2}\left(w_{k} r / a\right) & r \geq a
\end{array},\right.
$$

where $j_{0}$ and $K_{0}$ are respectively the Bessel and the modified Bessel functions, $u_{k}$ and $w_{k}$ imply the transverse propagation constants of the $L P_{01}$ mode, $r$ and $a$ are respectively the radial coordinate and the core radius, and $N_{T}$ is the total dopant concentration per unit length. It is given by the relation $N_{T}=2 \pi \int_{0}^{\infty} n_{T}(r) \times r d r$, where $n_{T}(r)$ is the transverse distribution function for thulium.

The function chosen should be flexible enough so that it can easily be adapted to as many profiles as possible, and it should contain as small number of parameters as possible. Issuing from these conditions, the best transverse distribution function has been suggested [4] to be

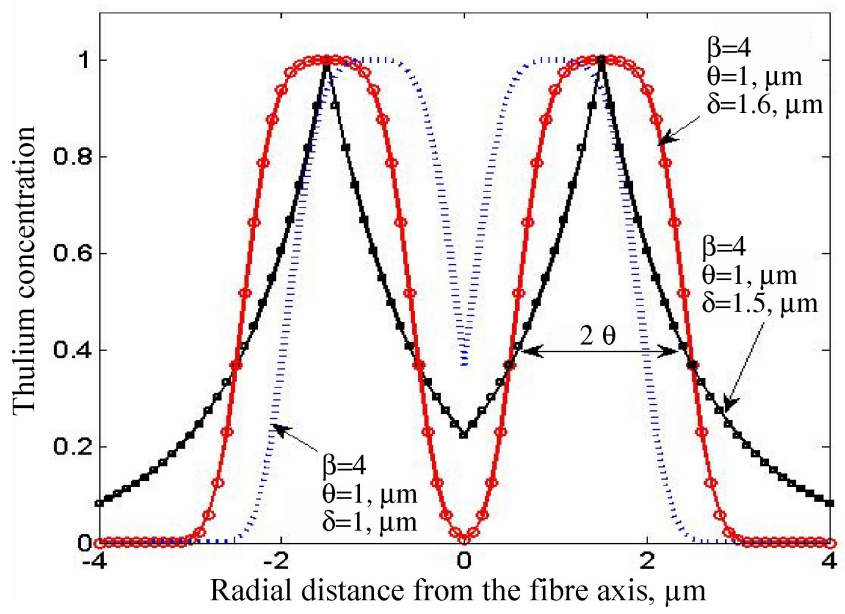

Fig. 2. TTDP as a function of radial distance from the fibre axis, $\mu \mathrm{m}$
$n_{T}(r)=n_{T, \max } \exp \left\{-\left[\frac{|r-\delta|}{\theta}\right]^{\beta}\right\}$

where $n_{T, \max }$ is the maximum thulium concentration per unit volume. The variables $\theta, \beta$ and $\delta$ represent the dopant radius, the roll-off factor of the profile and the radial position of the profile peak, respectively. These profile parameters govern the shapes of the profile for different TDFs.

Fig. 2 shows three different distribution profiles for the thulium concentration represented as 


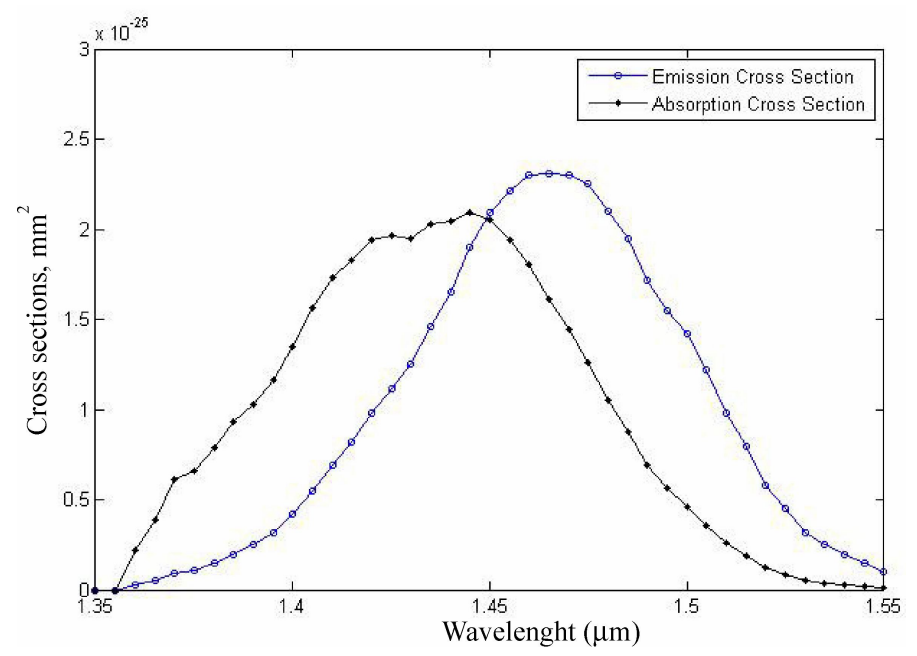

Fig. 3. Emission and absorption cross section spectra for the TDFA estimated using a modified McCumber's relation [6]. functions of the distance from the fibre axis.

As seen from Fig. 2, the parameter $\theta$ can be used for modifying the broadness of the profile, $\beta$ determines its steepness, and $\delta$ indicates the depth of a profile 'dip' which is approximately at the centre of the profile. By increasing $\beta$ from 1 to 4 , one can adjust the profile steepness so that the theoretical step is achieved at a certain point, while

deeper dips can be achieved by increasing $\delta$ from 1.0 to $1.5 \mu \mathrm{m}$, as depicted in Fig. 2. Fig. 3 shows the spectra of the emission and absorption cross sections for the TDFs used in this study. The spectroscopic parameters used in our analysis are summarised in Table 1.

Table 1. Parameter values used in our numerical simulations.

\begin{tabular}{|l|l|l|l|}
\hline Parameter & Unit & Symbol & Value \\
\hline Thulium concentration & $1 / \mathrm{m}^{3}$ & $P$ & $1.68 \times 10^{25}$ \\
\hline Numerical aperture & & $N A$ & 0.3 \\
\hline Fibre length & $\mathrm{m}$ & $L$ & 20 \\
\hline 800 -nm ASE bandwidth & $\mathrm{nm}$ & $\Delta v_{8}$ & 10 \\
\hline 1800 -nm ASE bandwidth & $\mathrm{nm}$ & $\Delta v_{18}$ & 100 \\
\hline ASE bandwidth at the S-band & $\mathrm{nm}$ & $\Delta v$ & 2 \\
\hline 1050 -nm pump absorption cross section & $\mathrm{m}^{2}$ & $\sigma_{p 02}$ & $1.1 \times 10^{-27}$ \\
\hline 1050 -nm pump absorption cross section & $\mathrm{m}^{2}$ & $\sigma_{p 14}$ & $8.2 \times 10^{-25}$ \\
\hline 1050 -nm pump absorption cross section & $\mathrm{m}^{2}$ & $\sigma_{p 35}$ & $2.5 \times 10^{-27}$ \\
\hline 1650 -nm pump absorption cross section & $\mathrm{m}^{2}$ & $\sigma_{p 01}$ & $2 \times 10^{-26}$ \\
\hline Signal absorption cross section & $\mathrm{m}^{2}$ & $\sigma_{s a}$ & see Fig. 3 \\
\hline Signal stimulated emission cross section & $\mathrm{m}^{2}$ & $\sigma_{s e}$ & see Fig. 3 \\
\hline 800 -nm transition cross section & $\mathrm{m}^{2}$ & $\sigma_{03}, \sigma_{30}$ & $6.2 \times 10^{-25}$ \\
\hline 1800 -nm transition cross section & $\mathrm{m}^{2}$ & $\sigma_{01}, \sigma_{10}$ & $5.2 \times 10^{-25}$ \\
\hline Radiative decay rate & $1 / \mathrm{s}$ & $A_{10}$ & 172.4 \\
\hline Radiative decay rate & $1 / \mathrm{s}$ & $A_{30}$ & 702.8 \\
\hline Radiative decay rate & $1 / \mathrm{s}$ & $A_{50}$ & 676.3 \\
\hline Radiative decay rate & $1 / \mathrm{s}$ & $A_{52}$ & 492.9 \\
\hline Non-radiative decay rate & $1 / \mathrm{s}$ & $A_{43 n r}$ & 52976 \\
\hline Non-radiative decay rate & $1 / \mathrm{s}$ & $A_{21 n}$ & 165626 \\
\hline
\end{tabular}

Ukr. J. Phys. Opt. 2012, V13, №2 


\section{Results and discussion}

The overlap factors resulted from different $\beta$ and $\theta$ values are depicted in Fig. 4. With increasing $\theta$ value, the intensity associated with the doping thulium ions is spread out from the centre of the core. This causes lower portions of thulium ions to be overlapped with the optical mode and, therefore, reduces the performance of the amplifier. As the $\beta$ value increases, however, the ion density at the centre of the core decreases for certain values of $\theta$, resulting in higher overlap factors. Fig. 5 shows the effect of both the $\beta$ and $\delta$ parameters on the overlap factor at $\theta=2.5 \mu \mathrm{m}$. As seen from Fig. 5 , all the $\mathrm{Tm}^{3+}$ ions redistribute towards the centre of the core as $\beta$ decreases, resulting in higher overlapping between the doping ions and the fibre mode. Moreover, the overlap factor decreases with increasing $\delta$ value (see Fig. 5). Then we have an increase in the deepness at the middle of the profile so that the $\mathrm{Tm}^{3+}$ ions populating outer regions of the core can only interact with lower-intensity pumps [13].

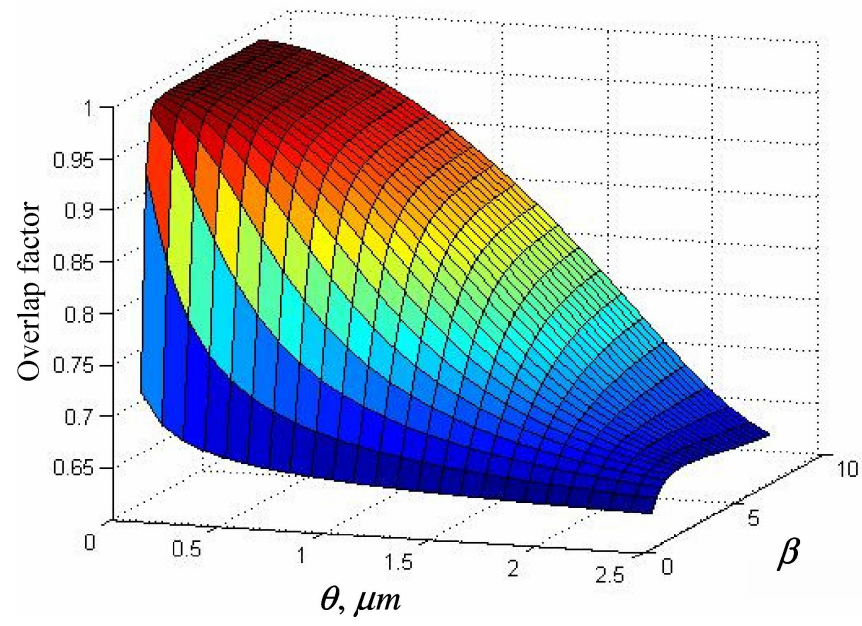

Fig. 4. Overlap factor of TDFA as a function of $\theta$ and $\beta$ parameters.

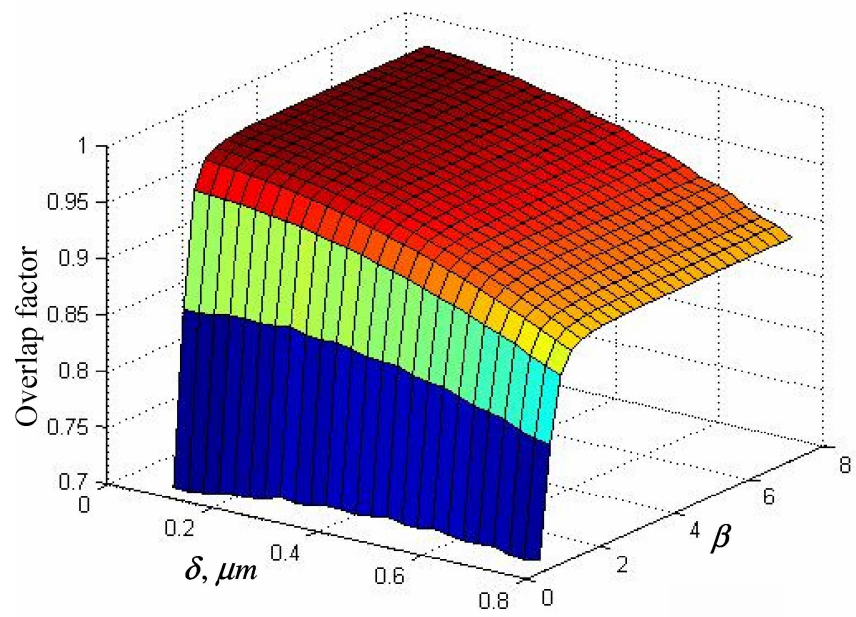

Fig. 5. Overlap factor of TDFA as a function of $\delta$ and $\beta$ parameters. 
Fig. 6a and Fig. 6b demonstrate the trends observed respectively for the gain and the noise of the TDFA at different $\theta$ and $\beta$ values. In our simulation, the input signal and the pump powers is fixed at $-30 \mathrm{dBm}$ and $250 \mathrm{~mW}$, respectively, while the input signal wavelength is equal to $1460 \mathrm{~nm}$. The TDF length is chosen to be $20 \mathrm{~m}$. As seen from Fig. 6a, the gain increases with increasing $\beta$ but decreases with increasing $\theta$ value from 1 up to $3 \mu \mathrm{m}$. This can be attributed to the influence of the overlap factor, which increases with increasing $\beta$ and decreases with increasing $\theta$ (see Fig. 4). On the other hand, the noise figure increases with increasing $\theta$ value (see Fig. 6b). It is known that the forward ASE power $P_{A S E}$ can be reduced when the pump power is larger at the input of the TDF [14]. The increase in $P_{A S E}$ has undesirable influence on the noise figure as described numerically by the equation [14]

$$
N F=\frac{1}{G}+\frac{2 P_{A S E}}{G h v},
$$

with $G$ being the gain of the amplifier and $h v$ the photon energy.

With increasing $\theta$, the intensity related to the thulium ions doping the centre of the core is spread out. This distribution causes a lower amount of the thulium ions to be overlapped with the optical mode and so lower gain values. However, as the $\beta$ value increases, the ion density at the centre of the core decreases beginning from certain $\theta$ values. This results in higher overlap factor and so higher gain. At the $\theta$ values lower than $1.5 \mu \mathrm{m}$, the thulium ion density is very high at the centre of the fibre so that the gain decreases due to quenching effects.
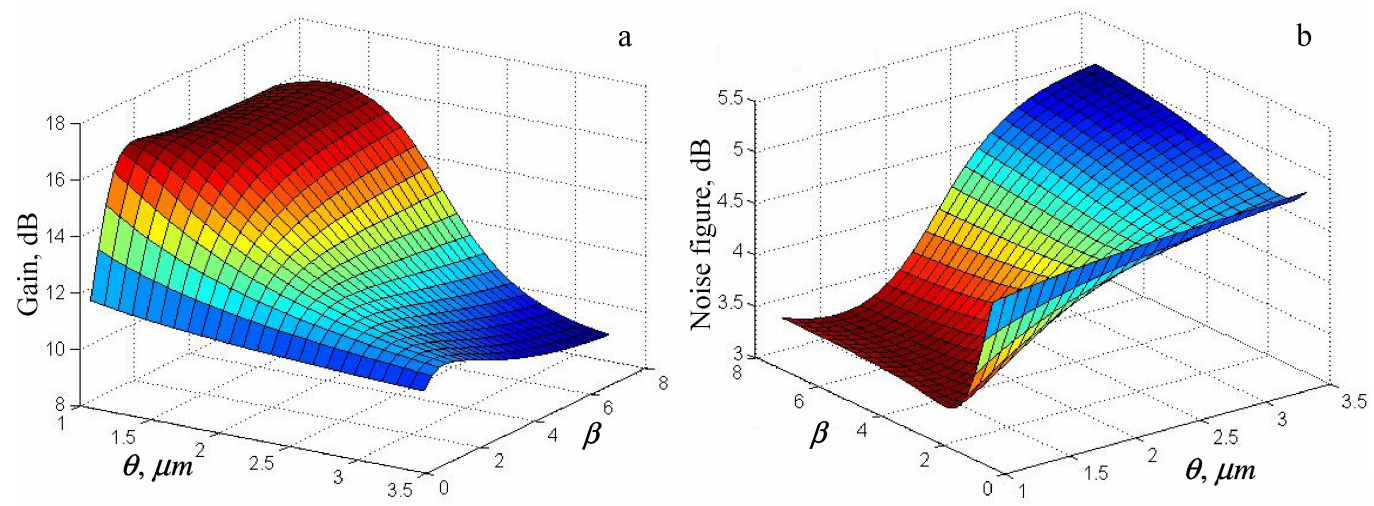

Fig. 6. TDFA gain (a) and noise figure (b) trends as functions of $\theta$ and $\beta$ parameters.

The effect of both the $\beta$ and $\delta$ parameters on the gain and noise figures has also been studied at $\theta=2.5 \mu \mathrm{m}$ (see the results shown in Fig. 7a and Fig. 7b). As seen from Fig. 7a, there is a high gain increment slope at $\beta=0.7-2$. Due to increasing $\beta$ values, all of the $\mathrm{Tm}^{3+}$ ions are distributed near the centre of the core. This phenomenon results in higher overlap between the doping ions and the light mode inside the fibre. As for Fig. 7b, one can see that increasing $\delta$ value produces decrease in the gain. The dip in the middle of the profile becomes deeper so that the $\mathrm{Tm}^{3+}$ ions that populate the outer regions of the core can only interact with lower pump intensities $[4,13]$.

Fig. 8 shows the gain and the noise figure for a relatively low doping radius $(\theta=1.2 \mu \mathrm{m})$. Here the input signal and pump powers are fixed at $-30 \mathrm{dBm}$ and $250 \mathrm{~mW}$, respectively. If Ukr. J. Phys. Opt. 2012, V13, №2 
compared to that observed at $\theta=2.5 \mu \mathrm{m}$, we observe a gain reduction of about $1.5 \mathrm{~dB}$ for low doping radiuses. Under such conditions, all the thulium ions are centred near the core so that a higher overlap occurs at different $\beta$ and $\delta$ values [5].
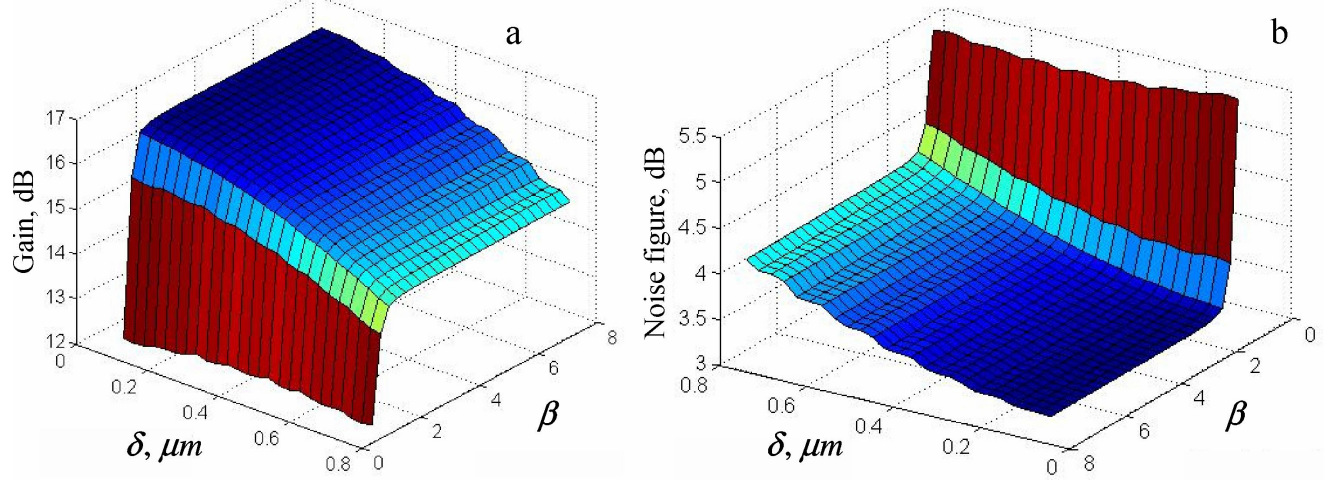

Fig. 7. Gain (a) and noise figure (b) of TDFA as functions of $\beta$ and $\delta$ parameters $(\theta=2.5 \mu \mathrm{m})$.
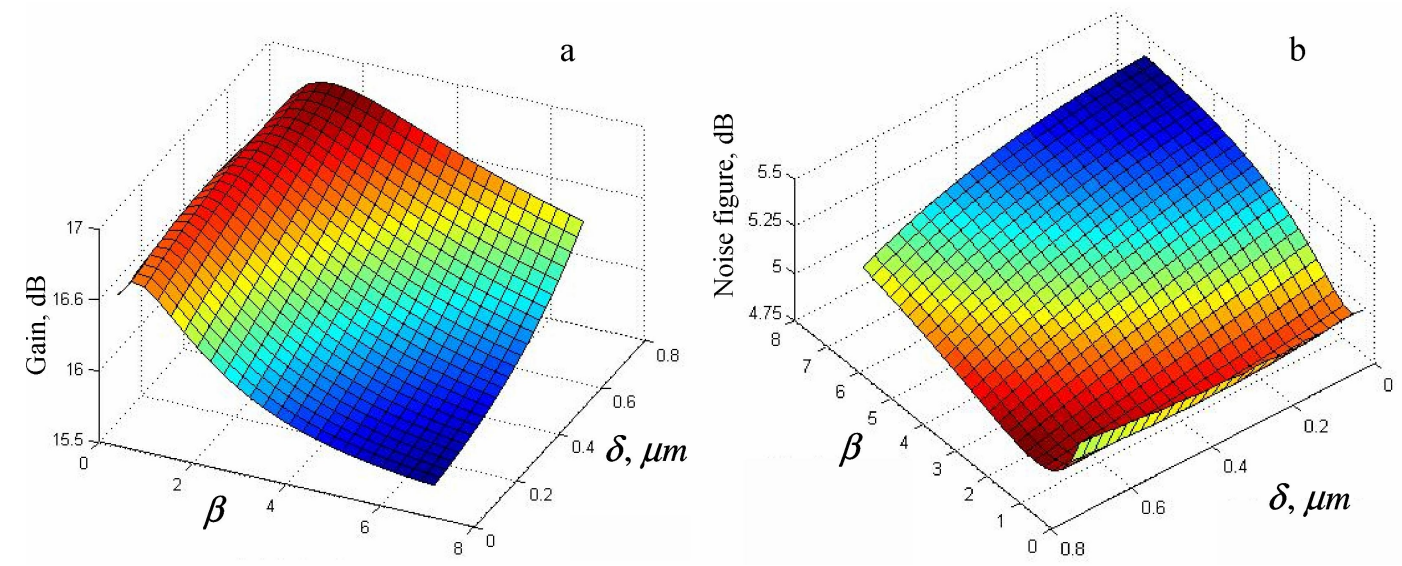

Fig. 8. Gain (a) and noise figure (b) of TDFA as functions $\beta$ and $\delta$ parameters $(\theta=1.2 \mu \mathrm{m})$.

\section{Conclusion}

We have studied the effect of transverse thulium distribution in TDFs on the performance of Sband TDFAs. The TTDP is shown to be essential in determining the overlap factor, which affects the absorption and emission dynamics of the TDFA. In particular, the overlap factor increases as the $\beta$ parameter, which governs the distribution profile, does so and it decreases with increasing $\theta$ parameter. The TDFA gain follows the same trend. On the other hand, the TDFA noise figure increases with increasing $\theta$ value, due to suppression of the ASE.

\section{References}

1. Harun S W, Dimyati K, Jayapalan K K and Ahmad H, 2007. An overview on S-band erbiumdoped fiber amplifiers. Laser Phys. Lett. 4: 10-15.

2. Komukai T, 1995. Upconversion pumped thulium-doped fluoride fiber amplifier and laser operating at $1.47 \mu \mathrm{m}$. IEEE Quant. Electron. 3: 1880-1888.

3. Peterka P, Faure B, Blanc W, Karásek M and Dussardier B, 2004. Theoretical modelling of S- 
band thulium-doped silica fibre amplifiers. Opt. Quant. Electron. 36: 201-212.

4. Martin J C, 2001. Erbium transversal distribution influence on the effectiveness of a doped fiber: optimization of its performance on the effectiveness of a doped fiber: optimization of its performance. Opt. Commun. 194: 331-339.

5. Pfeiffer $\mathrm{T}$ and Bulow $\mathrm{H}, 1992$. Analytical gain equation for erbium-doped fiber amplifiers including mode field profiles and dopant distribution. IEEE Photon. Technol. Lett. 4: 449451.

6. Agger S D and Povlsen J H, 2006. Emission and absorption cross section of thulium doped silica fibers. Opt. Express. 14: 50-57.

7. Kasamatsu T, Yano $\mathrm{Y}$ and Ono T, 2002. 1.49- $\mu \mathrm{m}$-band gain-shifted thulium-doped fiber amplifier for WDM transmission systems. J. Lightwave Technol. 20: 1826-1838.

8. Peterka P, Kasik I, Dhar A, Dussardier B and Blanc W, 2011. Theoretical modeling of fiber laser at $810 \mathrm{~nm}$ based on thulium-doped silica fibers with enhanced ${ }^{3} \mathrm{H}_{4}$ level lifetime. Opt. Express. 19: 2773-2781.

9. Evans C A, Ikonic Z, Richards B, Harrison P and Jha A, 2009. Theoretical modeling of a $2 \mu \mathrm{m}$ $\mathrm{Tm}^{3+}$-doped tellurite fiber laser: the influence of cross relaxation. J. Lightwave Technol. 27: 4026-4032.

10. Yam S S H and Kim J, 2006. Ground state absorption in thulium-doped fiber amplifier: experiment and modeling. IEEE J. Quant. Electron. 12: 797-803.

11. Desurvire E. Erbium-doped fiber amplifiers: principles and applications. New York: John Wiley \& Sons (1994).

12. Agrawal G P. Fiber-optic communication systems. New York: John Wiley \& Sons (1997).

13. Hassani A, Arzi E and Seraji F, 2007. Intensity based erbium distribution for erbium doped fiber amplifiers. Opt. Quant. Electron. 39: 35-50.

14. Emami S D, Hajireza P, Abd-Rahman F and Ahmad H, 2010. Wide-band hybrid amplifier operating in S-band region. Progr. Electromagnet. Res. 102: 301-313.

Emami S.D., Abdul-Rashid H.A., Ahmad H., Ahmadi A. and Harun S.W., 2012. Effect of transverse distribution profile of thulium on the performance of thulium-doped fibre amplifiers. Ukr.J.Phys.Opt. 13: $74-81$.

Анотація. Вивчаються чисельні моделі для різних поперечних профілів розподілу тулію, що характеризують волокна, які використовуються як волоконні підсилювачі. У нашій моделі розглянуто фактор перекриття $i$ динаміку поглинання/випромінювання. Базуючись на радіальній функиії розподілу тулію $n_{T}(r)=n_{T, \max } \exp \left[-(|r-\delta| / \theta)^{\beta}\right]$, показано, що підсилення зростає з ростом параметра $\beta i$ зменшується при зростанні - $\theta$ від 1 до 3 мкм, у зв'язку з впливом фактору перекриття, який впливає на динаміку поглинання $i$ випромінювання $y$ волоконних підсилювачах. Фактор перекриття зростає з ростом $\beta i$ зменшується з ростом значення $\theta$. Шум фактор зростає з ростом $\theta$, відповідно до суперпозииії підсиленого спонтанного випромінювання. 